Document downloaded from:

http://hdl.handle.net/10251/67077

This paper must be cited as:

Conejero García, A.; Vilarino-Feltrer, G.; Martínez Ramos, C.; Monleón Pradas, M.; Vallés Lluch, A. (2015). Channeled polymeric scaffolds with polypeptide gel filling for lengthwise guidance of neural cells. European Polymer Journal. 70:331-341. doi:10.1016/j.eurpolymj.2015.07.033.

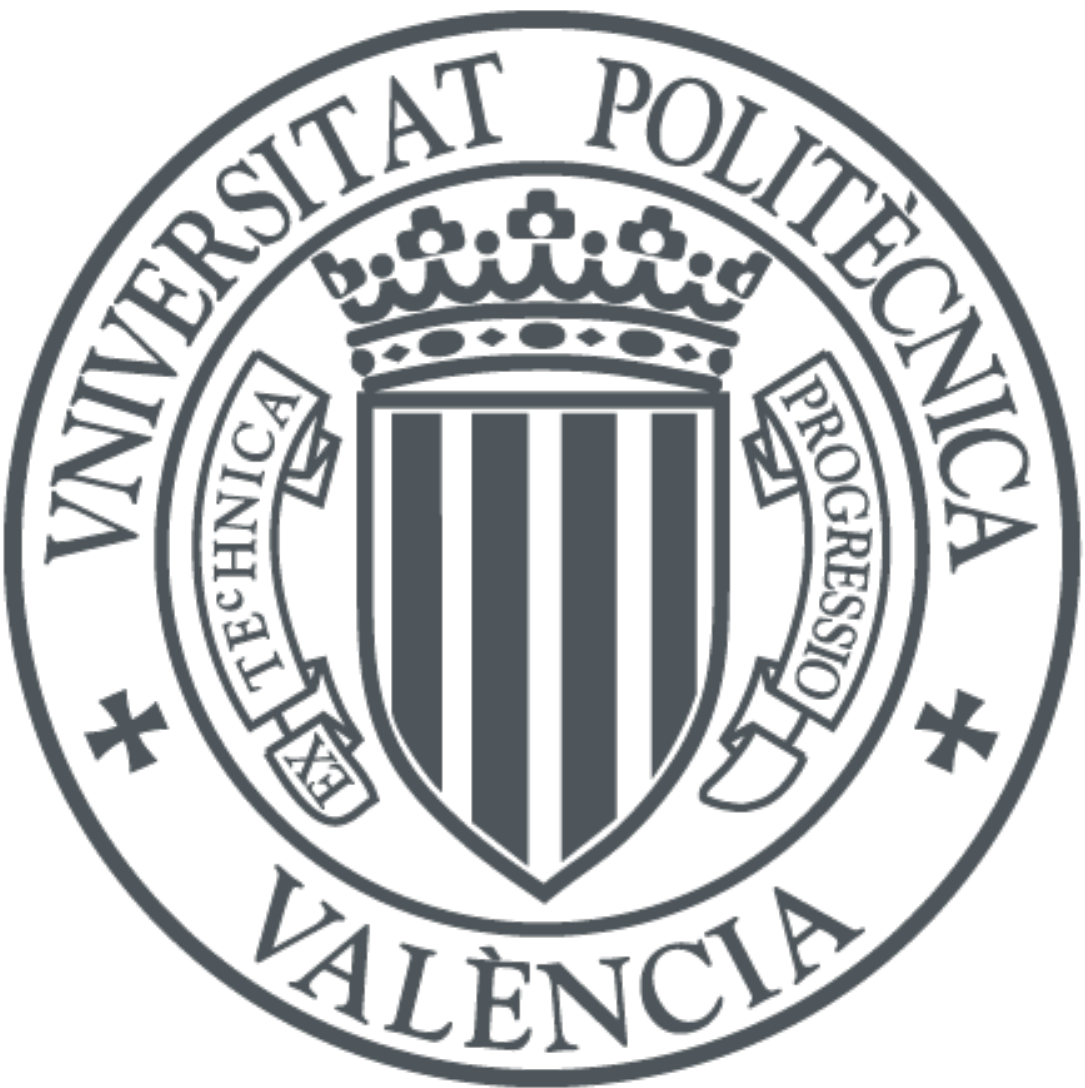

The final publication is available at

http://dx.doi.org/10.1016/j.eurpolymj.2015.07.033

Copyright Elsevier

Additional Information 


\title{
Channeled polymeric scaffolds with polypeptide gel filling for lengthwise guidance of neural cells
}

\author{
Conejero-García ${ }^{1 \#}$, Vilariño-Feltrer $G^{1 \#}$, Martínez-Ramos $C^{1}$, Monleón Pradas $M^{1,2}$, Vallés- \\ Lluch $\mathbf{A}^{\mathbf{1}^{*}}$ \\ ${ }^{1}$ Center for Biomaterials and Tissue Engineering, Universitat Politècnica de València, C. de Vera s/n, \\ 46022, Valencia, Spain \\ ${ }^{2}$ Networking Research Center on Bioengineering, Biomaterials and Nanomedicine, Valencia, Spain \\ *Corresponding author. Tel.: +34963877000; fax: +34963877276. E-mail: avalles@ter.upv.es \\ \# equal contribution
}

\begin{abstract}
CNS damages are often irreversible since neurons of the central nervous system are unable to regenerate after an injury. As a new strategy within the nervous system tissue engineering, multifunctional systems based on two different biomaterials to support axonal guidance in damaged connective tracts have been developed herein. These systems are composed of a channeled scaffold made of ethyl acrylate and hydroxyethyl acrylate copolymer, $\mathrm{P}(\mathrm{EA}-\mathrm{co}-\mathrm{HEA})$, with parallel tubular micropores, combined with an injectable and in situ gelable self-assembling polypeptide (RAD16-I) as pores filler. The polymer scaffold is intended to provide a three-dimensional context for axon growth; subsequently, its morphology and physicochemical parameters have been determined by scanning electron microscopy, density measurements and compression tests. Besides, the hydrogel acts as a cell-friendly nanoenvironment while it creates a gradient of bioactive molecules (nerve growth factor, NGF) along the scaffolds channels; the chemotactic effect of NGF has been evaluated by a quantitative ELISA assay. These multifunctional systems have shown ability to keep circulating NGF, as well as proper short-term in vitro biological response with glial cells and neural progenitors.
\end{abstract}

Keywords: scaffold, NGF, RAD16-I, neural conduct, neuroglia, axonal growth. 


\section{Introduction}

Central nervous system (CNS) is particularly vulnerable to damages and defects like strokes or diseases, and hence medicine has traditionally made an intense effort to discover effective treatments upon investigation of their onset and symptoms. In Parkinson's disease, e.g., an acute loss of dopaminergic neurons in the substantia nigra occurs, followed by a lack for dopamine in the striatum [1,2]. Although mechanisms are still unclear [3-5], latest discoveries improved our knowledge about where the disease begins and how this effect expands [6]. However, all CNS damages worsen soon after their onset due to the low rate of regeneration in the nervous system. This regeneration is only effective in hippocampus and olfactory bulb, although there are evidences of neurogenesis in adult mammals in several additional areas, including striatum and substantia nigra [7].

Neural stem cells (NSCs) present some features such as a multipotent nature and a common cluster conformation known as proliferative neurospheres in response to defined signals; this is why neural stem cell transplantation has been considered as a promising strategy for the treatment of lesions $[\mathbf{5 , 8}]$. However, the effectiveness of this therapy is limited because of the lack of support from the host damaged environment and a low cell survival rate after transplantation.

In order to stop or effectively revert the progression of disease, synthetic biomaterials have been widely tested to avoid the drawbacks of current therapies. Indeed, they are one of the cornerstones in tissue engineering, as they might support cell grafting by providing a physical three-dimensional context to lodge and protect them, maximizing thus cell transplantation efficiency [9-11]. The use of scaffolds with selected properties (topography, chemical interactions, mechanical modulus...) can also improve chemical 
cell-(protein)-biomaterial and cell-cell communication and, subsequently, cell adhesion, proliferation, migration, and differentiation $[\mathbf{1 0 , 1 2}]$.

Degradable materials are intended just as temporary supports and are thus the most employed ones; however, there is room for their opposites in this field, for example in CNS degenerative defects that are triggered or aggravated by gene-derived cues [13]. In general, the use of non-degradable polymers is desirable when the host tissue is not able to ensure a functional recovery by itself, and supply a long-term support in terms of three-dimensional innocuous protective environment. For instance, elastomeric polymers, like those made of ethyl acrylate (EA), or their copolymers with hydroxyethyl acrylate (HEA), can also interact with cell integrins and other membrane receptors via adsorbed proteins to modulate cell response, due to their paired hydrophobic-hydrophilic domains. Namely, P(EA-co-HEA) 90/10 w/w scaffolds have previously demonstrated good biocompatibility in in vitro and in vivo studies, allowing cells to adhere, migrate and differentiate [14-17].

Likewise, extracellular matrix-like hydrogels such as RAD16-I, in spite of being difficult to handle, have widespread experimental and clinical applications, including cell culture, drug delivery and regeneration of CNS tissue, cardiac tissue or cartilage and bone growth [18-22], and such an edge has to be considered to mimic realistically a complex tissue-like structure.

To fully make the most of the tissue engineering potential, in recent years numerous bioactive stimuli such as neurotrophic factors, electromagnetic fields and extracellular matrix molecules have been used to fill the short-term deficiencies in the site of injury, together with biomaterials. Bioactive nerve growth factor (NGF), brain-derived neurotrophic factor (BDNF), fibroblast growth factor (FGF) and glial growth factor (GDNF) are some of the most extensively molecules explored as treatments for CNS 
injuries [23-25]. In particular, NGF has also been tested with different delivery systems using fibrin, gelatin or other polymers, leading to an improvement of axon extension of neural cells $[\mathbf{2 6 , 2 7 ]}$.

Acrylate spongy or grid-like scaffolds have been combined with RAD16-I gel and their biological performance has already been studied in vitro and in vivo [14,28-31]. Notwithstanding, the microarchitecture of scaffolds herein used is particular, in the sense that channels are smaller in diameter, lengthwise oriented and not connected between them; these features make them potential candidates for dentin regeneration, which has been the case in $[\mathbf{3 2 , 3 3}]$ and for neural regeneration [17]. In this work, the in vitro biological response of $\mathrm{P}(\mathrm{EA}-\mathrm{co}-\mathrm{HEA})$ 90/10 scaffolds with parallel channels filled with a self-assembling polypeptide (RAD16-I) has been evaluated to select the material substrate, in terms of how crucial the channels diameter is to attain guided axon extension and the potential interest of incorporating the RAD16-I filler to improve cell proliferation and migration. The gel allows the diffusion of chemicals from one edge to the other, together with the colonization by cells seeded up there. Thus, it has been assessed whether the chemotaxis of NGF on a co-culture of Schwann cells and neurospheres along the scaffold channels improves axon regeneration, besides neural cell survival, proliferation and differentiation.

\section{Materials and methods}

\subsection{Reagents and materials}

Reagents were purchased from Sigma-Aldrich, except the N-N-dimethylformamide (Scharlab). Schwann cells and culture media were purchased from Innoprot, MTS assay kit from Promega, and putrescine, progesterone, sodium selenite, apo-t-transferrin, insulin, paraformaldehyde, Tween-20 and BSA from Sigma-Aldrich. DMEM/F12, glucose, HEPES, L-glutamine, penicillin/streptomycin, BDNF, FGF, StemPro acutasse, 
Quant-iT DNA assay, Alexa goat anti-rabbit 488 and DAPI were obtained from Life Technologies, polyclonal rabbit anti-GFAP from Dako Cytomation and NGF sandwich ELISA kit ChemiKine from Millipore.

\subsection{Preparation of $P(E A-c o-H E A)$ scaffolds}

$\mathrm{P}$ (EA-co-HEA) scaffolds were fabricated by thermal polymerization, using glass tubes (4 $\mathrm{mm}$ in diameter) filled with a bundle of polyacrylonitrile (PAN) fibers with two different diameters: 10 and $50 \mu \mathrm{m}$. The fibers were set parallels and stretched, as described in [32]. Briefly, a monomeric solution was prepared with ethyl acrylate (EA) and hydroxyethyl acrylate (HEA), 90/10\% w/w, respectively, adding ethylene glycol dimethacrylate (EGDMA; 1\% wt) as crosslinker and benzoyl peroxide (BPO; 0.5\% wt) as thermal initiator. The solution was stirred and vacuum-injected into the molds, which were sealed and cured for $24 \mathrm{~h}$ at $60^{\circ} \mathrm{C}$. After this first polymerization step, temperature was raised to $90^{\circ} \mathrm{C}$ for $24 \mathrm{~h}$ more, to post-polymerize any unreacted reagents. To obtain porous scaffolds, the bulk polymeric blocks were cut into sections of $6 \mathrm{~mm}$ in length and rinsed in N-N-dimethylformamide (DMF) for $72 \mathrm{~h}$, changing the solution every 12 $\mathrm{h}$, to dissolve the PAN fibers. To remove DMF from the scaffolds, they were next rinsed for $48 \mathrm{~h}$ in ethanol, replaced for fresh ethanol each $8 \mathrm{~h}$. Finally, they were gradually rehydrated with ethanol $85,70,50,30$ and $0 \%$ vol. each hour to prevent channels from collapsing, and vacuum dried.

\subsection{Characterization of channeled scaffolds}

Micrographs of transversal and longitudinal scaffold slices were taken in a scanning electron microscope (SEM, JSM-6300, JEOL). The scaffolds pores diameter and the percentage of porous area were quantified using ImageJ (National Institutes of Health, USA). Density of scaffolds having $50 \mu \mathrm{m}$ diameter pores was measured by Archimedes' 
method with a precision scale (AX205, Mettler Toledo), weighing the samples in dry conditions and immersed in n-octane (Sigma-Aldrich). Their elastic moduli were obtained from compression measurements in a Seiko TMA/SS6000 dilatometer, from 0 to $1500 \mathrm{mN}$ at $100 \mathrm{mN} / \mathrm{min}$ in the direction of the channels.

\subsection{Bicompartmental systems}

To evaluate the NGF diffusion rate and the chemical gradient created, bicompartmental systems were designed, as shown in Figure 1A. They consisted in a microcentrifuge conic tube (upper part) with a scaffold longitudinally fitted in and properly sealed with thermofusible glue. Watertightness was tested by forced diffusion of a water suspension of polymethyl methacrylate (PMMA) beads through the scaffold channels. The diameters of the beads used for the two different suspensions tested were in the range of 100 and $200 \mu \mathrm{m}$ in one case and below $100 \mu \mathrm{m}$ in the other.

Bicompartmental systems intended for cell cultures were sanitized in ethanol $70 \%$ for 2 h. Later they were rinsed in sterile water for $10 \mathrm{~min}$. One group was then treated with an aqueous solution of RAD16-I $0.15 \%$ w/v by vacuum pumping it through the scaffolds channels (by several syringe strokes). To assess the complete filling of the channels with the polypeptide, CryoSEM (JSM541 with Oxford CT 1500 cryogenic unit, JEOL) micrographs of longitudinal cuts were taken.

\subsection{Cell expansion}

Rat Schwann cells (SCs) from a commercial line (Innoprot) were maintained at $37^{\circ} \mathrm{C}$ and $5 \% \mathrm{CO}_{2}$ in a $75 \mathrm{~cm}^{2}$ flask with growth factors-supplemented culture medium (Innoprot). All experiments were carried out at fifth cell passage. 
At the same time, neurospheres (NSs) transfected with red fluorescent protein (RFP) were expanded at $37^{\circ} \mathrm{C}$ and $5 \% \mathrm{CO}_{2}$ with neural pre-differentiation culture medium (DMEM/F12, 30\% glucose, 7.5\% NaHCO3, HEPES 1M, apo-t-transferrin, insulin, 1X putrescine, $2 \mathrm{mM}$ progesterone, $3 \mathrm{mM}$ sodium selenite, L-glutamine $2 \mathrm{mM}, 100 \mathrm{U} \mathrm{ml}-1$ penicillin, $100 \mu \mathrm{g} \mathrm{ml}-1$ streptomycin, 0.2\% heparin, 1\% FBS, BDNF $20 \mathrm{ng} / \mathrm{mL}$ and FGF $10 \mathrm{ng} / \mathrm{ml}$ ). The culture medium was replaced every 3-4 days and, after 7 days of culture, the NSs clusters were mechanically and enzymatically (StemPro accutase) dissociated.

\subsection{Cell seeding and viability assay}

Bicompartmental systems were inserted in a 96-well plate and $1.5 \cdot 10^{5} \mathrm{SCs}$ were seeded on the upper surface of each scaffold, with and without RAD16-I in their pores, and on polystyrene coverslips as a two-dimensional positive controls. Schwann cell medium was added and cell viability and proliferation were determined (two $6 \mathrm{~mm}$ long scaffolds per group) after 1, 7 and 10 days of culture by means of a colorimetric assay (MTS assay, Promega) and readings at $490 \mathrm{~nm}$ in a multiplate reader spectrophotometer (VICTOR 1420, Perkin Elmer).

The constructs with scaffolds having $50 \mu \mathrm{m}$ diameter pores were also used for a DNA fluorometric assay. After 10 days of culture, samples were frozen at $-80^{\circ} \mathrm{C}$ and thawed 3 times (24h each) to lyse cells and allow the reagent (Quant-iT DNA) to bond to DNA chains, to measure fluorescence with the spectrophotometer. Bovine thymus DNA was used to convert fluorescence units into cell number.

In a subsequent assay, $10^{5} \mathrm{SCs}$ were again seeded in bicompartmental systems with SCs culture medium for $24 \mathrm{~h}$. The bottom part of the bicompartmental systems was filled with mix medium (50\% vol. Schwann rat medium, 50\% vol. neural differentiation 
medium) and $10 \mathrm{ng} / \mathrm{ml} \mathrm{NGF.} \mathrm{At} \mathrm{the} \mathrm{top} \mathrm{of} \mathrm{the} \mathrm{system} 10^{5}$ rat NSs were then seeded and mix medium (without NGF, to establish a downwards gradient) was added. Cell viability was measured by MTS as explained before but after 1, 3 and 7 culture days in this case, four scaffolds per time.

\subsection{Immunocytochemistry}

At the end of culture time ( 7 days) the bicompartmental systems were rinsed with $0.1 \mathrm{M}$ PBS at $\mathrm{pH} 7.4$, fixed for $20 \mathrm{~min}$ in $4 \%$ paraformaldehyde and their unspecific protein regions were blocked for 30 min with a solution containing PBS, 0.1\% Tween 20 and $1 \%$ BSA. Cells were then incubated overnight at $4^{\circ} \mathrm{C}$ with rabbit anti-GFAP (Life Technologies, 1:100 dilution in PBS) and, next, scaffolds were incubated $2 \mathrm{~h}$ with Alexa goat anti-rabbit 488 (1:200 dilution in PBS). GFAP is expressed in glial cells, stemming from the SCs or the NSs subpopulations. Finally, cells nuclei were dyed with DAPI (1:5000 dilution in PB 0.1M). Scaffolds were withdrawn from the bicompartmental systems and cryo-protected by immersion in $0.1 \mathrm{M}$ PB with $30 \%$ sucrose for $1 \mathrm{~h}$ at room temperature. Then, they were soaked in OCT Compound (Leica Biosystems) for $2 \mathrm{~h}$ and frozen at $-30^{\circ} \mathrm{C}$ overnight in order to cut them into $100 \mu \mathrm{m}$-thick longitudinal slices with a cryostat (HM520, Microm) for their observation under confocal and optical fluorescence microscopes (Olympus FV1000 and Nikon Eclipse $80 \mathrm{i}$, respectively).

\subsection{Protein $(N G F)$ release study}

Firstly, in order to estimate the NGF release rate along the scaffolds pores, an acellular diffusion assay was carried out. Bicompartmental systems were placed in a 96-well plate with a $10 \mathrm{ng} / \mathrm{ml} \mathrm{NGF}$ aqueous solution in each well. Fresh distilled water was 
added in the upper compartment and aliquots were collected thereof after 15 and 30 $\min , 1,1.5,2,3,5$ and $7 \mathrm{~h}$.

Finally, to estimate the NGF effect over cell co-culture, the culture medium of the upper compartment was collected every time the medium was changed. Diffused NGF in both experiments was quantified by NGF sandwich ELISA kit. The absorbance of the each supernatant was read at $450 \mathrm{~nm}$ by the spectrophotometer. Three replicates per time point were scanned.

\section{Results}

\subsection{Characterization of scaffold/gel composite systems}

The procedure described above allowed to obtain $4 \mathrm{~mm}$ in diameter $6 \mathrm{~mm}$ long cylindrical scaffolds with parallel micrometric channels. By means of SEM images of cross and longitudinal sections of the scaffolds, the shape and the independence of the channels were validated, for those made with 10 (Figure $2 \mathrm{~A}$ and $\mathrm{C}$ ) as well as those with $50 \mu \mathrm{m}$-diameter fibers (Figure 2B, D). The 100 microns sections observed under the bright field (Figure 2E and F) revealed the continuity of the channels from end to end of the scaffolds.

The pores size and scaffold porosity were analyzed from SEM cross sections images analogous to Figure 2A and B (140 and 80 pores analyzed for the scaffolds with 10 and $50 \mu \mathrm{m}$ diameter channels, respectively). The channel diameter (Figure 2G) was inferred from the equation of the area of a circumference $\left(A=\pi r^{2}\right)$ by measuring its area and assuming a circularity higher than 0.75 each. The porosity (Figure $2 \mathrm{H}$ ), $\pi$, was determined according to equation (1), where the porous fraction of a cross section is considered to be constant along the scaffolds:

$$
\pi=\frac{V_{p}}{V_{T}}=\frac{A_{p} h}{A_{T} h}
$$


where $V$ means volume, $A$ is the area, $h$ is the height and the subscripts $p$ and $T$ mean pores and total, respectively.

The density obtained for the P(EA-co-HEA) scaffolds was $1.15 \pm 0.01 \mathrm{~g} / \mathrm{cm}^{3}$; this value corresponds to the polymeric solid matrix of the scaffold, regardless of the number of channels and their distribution. The Young modulus in the linear regions of the stressstrain curve (Figure 3 ) was determined as the slope for the strain intervals from 0 to $8.47 \%\left(\mathrm{E}_{1}=0.161 \mathrm{MPa}\right)$ and from 53.87 to $56.33 \%\left(\mathrm{E}_{2}=1.938 \mathrm{MPa}\right)$.

Figure 1A shows a scheme of the bicompartmental system, from which bottom part images $1 \mathrm{~B}$ and $\mathrm{C}$ were taken by bright field imaging to determine whether both compartments of the system were isolated hermetically except for the inner scaffold channels. In Figure 1B a random section of the well bottom was selected and several PMMA spheres with size smaller than $100 \mu \mathrm{m}$ can be seen. Nevertheless, when PMMA particles with a diameter over $100 \mu \mathrm{m}$ were used, only two of them were found in the $\mathrm{n}$ $=3$ runs of the experiment (one of which is shown in Figure 1C).

Regarding the inclusion of the RAD16-I gel inside the channels, the CryoSEM micrographs of longitudinal sections of scaffolds with $50 \mu \mathrm{m}$ diameter channels (Figure 4) showed a honeycomb-like web related to the sublimation residues of water contained in the RAD16-I gel filling the pores, where the solid P(EA-co-HEA) walls could be clearly identifiable with an appearance similar to that of Figures $2 \mathrm{C}$ and D.

\subsection{Cell viability}

The MTS assay carried out after SCs cultures at 1, 7 and 10 days allowed to confirm the biocompatibility of the scaffolds compared with a well bottom of a 96-well culture plate (as control) and to determine the optimal diameter of the scaffolds channels to allow SCs proliferation. As shown in Figure 5, the scaffolds with $50 \mu \mathrm{m}$ diameter channels 
behaved in very similar manner to the control for the first 7 days, whereas the $10 \mu \mathrm{m}$ diameter channels showed lower cell densities. A meaningful decrease was found for the control after 10 days of culture, but not for any scaffold, showing those of $50 \mu \mathrm{m}$ in diameter the best cell viability.

In the second MTS assay performed with scaffolds with $50 \mu \mathrm{m}$ diameter channels cocultured with SCs and NSs (this time using mix medium supplemented with NGF in the upper compartment, Figure 6A), the effect of the RAD16-I filling on cell proliferation was compared after 1, 3 and 7 days with cellular non-peptide filled scaffolds. A slight decrease in cell density over time can be observed for the scaffolds without RAD16-I, whereas the cells seemed to suffer an acute setback the first 3 days in the presence of RAD16-I from which they rapidly recovered up to levels comparable to those of the scaffolds without gel.

Moreover, the DNA fluorometry assay allowed to quantify the number of SCs in scaffolds both with and without RAD16-I gel after 10 days of culture. The crosscorrelation of standard plots of the fluorescence data of bovine thymus DNA for known SCs densities (Figure 6B top and bottom, respectively) allowed to calculate the amount of DNA in a single SC, i.e. $7.84 \pm 0.76 \mathrm{pg} / \mathrm{cell}$, and to represent the obtained data in the experiment with scaffolds with or without RAD16-I based on the cell number. As can be seen in Figure 6C, 10 days of culture with SCs entailed an increase of about $45 \%$ of the number of seeded cells when the scaffold channels were empty, but their population triplicated in the presence of RAD16-I gel in the pores.

\subsection{Immunocytochemical staining}

Fluorescence and confocal images after 7 days of SCs and NSs co-culture in scaffolds with $50 \mu \mathrm{m}$ diameter channels were taken, despite the P(EA-co-HEA) 90/10 selffluorescence (Figure 7A) that often prevented from achieving clear images in sections 
where the immunofluorescence intensity was weak. Even though, longitudinal sections of the seeding end of cellular scaffolds without or with RAD16-I inside their channels (Figures $7 \mathrm{~B}$ and $\mathrm{C}$, respectively) revealed a dense layer of cells on the outer surface (especially neuroglia, expressing GFAP -shown in green-) but also several cell nuclei (blue, DAPI) over the channels surface. Subscripted Figures 7B and C represent internal areas of scaffolds longitudinal sections, where some clusters of glial cells from different lineages can be observed interacting between them (Figures $7 \mathrm{~B}_{2}, \mathrm{~B}_{4}$ and $\mathrm{C}_{2}$ ), inasmuch cells with the cytoplasm stained in red derived from the RFP transfected NSs. Neuronlike cells with the elongated somata and sprouts (Figures $7 \mathrm{~B}_{1}$ and $\mathrm{C}_{1}$ ) could also be discerned expressing only RFP. Some of them were even tangled forming continuous oriented structures of up to $250 \mu \mathrm{m}$ long (Figures $7 \mathrm{~B}_{3}$ and $\mathrm{C}_{3}$ ).

\subsection{ELISA measurements}

Figure 8A shows the cumulative proportion of NGF that diffused through the scaffold channels, filled with RAD16-I and not, over time in the acellular diffusion experiment, on the basis of the total amount initially incorporated to the lower compartment. Considerable differences between groups were detected in it from the first hour and in the steady state, reached after 5-6 hours, although nor the scaffolds with RAD16-I neither those with empty channels released more than $25 \%$ of the loaded amount.

The NGF quantification data from the supernatants collected during the SCs-NSs coculture after 1, 3 and 7 days in scaffolds with and without RAD16-I showed (Figure 8B) that even more factor than that incorporated in the culture medium at the beginning of the culture (represented by the dashed line) diffused to the upper compartment. The over-generation of NGF stabilized in about 3 days and no significant differences were found between groups at the steady state. 


\section{Statistics}

All data distributions in the pore diameter determination, the porosity quantification and the MTS assays fitted a normal distribution, as for their shape parameters (kurtosis and skewness). The low sample size of the first MTS assay, which was an exploratory test, voided it for further statistical analysis. However, an ANOVA was performed for the data of the second MTS assay and the Tukey's HSD test was used to compare simultaneously the means of the different groups with a 95\% confidence level.

\section{Discussion}

The synthesis method used to prepare these scaffolds, based on the polymerization of the monomeric mixture in a fibers template followed by its leaching, led to obtain cylindrical scaffolds of $4 \mathrm{~mm}$ in diameter and $6 \mathrm{~mm}$ long with multiple parallel 10 or 50 $\mu \mathrm{m}$ diameter channels traversing them longitudinally (Figure 2). Although the porosity is slightly lower than in other three-dimensional scaffolds with different architectures, independently of the fibers diameter, this provides the benefit of avoiding the channels from intersecting or creating discontinuities, which could interfere with the intended guidance. Besides, these $\mathrm{P}(\mathrm{EA}-\mathrm{co}-\mathrm{HEA}) \quad 90 / 10$ scaffolds are based in known biocompatible polymers and have properties comparable to those of the tissue to be regenerated; firstly, their density is similar to that of the extracellular matrix of soft tissues, as it has been formerly stated $[\mathbf{3 2 , 3 4 ]}$. On the other hand, their Young's modulus is also of the order of that reported in similar assays for encephalon in mammalians [35], especially in the low strains stage (lower than 10\%, Figure 3), which corresponds to the most common strains found in a healthy nervous system. The elastic modulus of the copolymer is expected to decrease somewhat in a real physiological environment 
because of the $10 \%$ of HEA in its formulation, which is a hydrophilic polymer [32] compared to pure PEA [14].

The assembly to obtain bicompartmental systems proved tight enough to consider the upper and lower compartments to be isolated from each other, only directly connected by the inner scaffold channels (Figure 1), through which liquids, molecules and particles smaller than the channels diameter can flow. Still, a slow diffusion of liquids and molecules through the polymeric matrix of the scaffolds cannot be excluded, which is basically attributed to the fraction of hydrophilic HEA in it.

By means of the vacuum protocol the scaffolds channels were properly filled with the RAD16-I solution. The salts-mediated in situ gelation of the peptide was successful for $6 \mathrm{~mm}$ long channels. Its three-dimensional web-like structure (Figure 4) is similar to that of the extracellular matrix under CryoSEM: a cell-friendly nanoenvironment that cells isolated in the conduits can cover from the end of the scaffold where they are seeded to the other.

As for the cell response, the bare P(EA-co-HEA) 90/10 channeled scaffolds showed to be at least as biocompatible as the polystyrene cover used in cell culture plates (Figure 5). The scaffolds with $50 \mu \mathrm{m}$ diameter channels allowed SCs to proliferate faster than those with $10 \mu \mathrm{m}$ channels, especially after 7 days of culture; this can be due to the volume restriction of the smaller diameter channels, similar in size to cells somata. Thus, although the number of channels per unit area is greater in scaffolds with $10 \mu \mathrm{m}$ channels, cells have little migration space and they may block themselves the access of nutrients from the opposite end. The sharp decrease in cell population observed on the control surface was probably triggered by the SCs high density reached after 10 days, which probably drove them to confluence and to the subsequent lack of oxygen and 
nutrients in the lower cell layers, as other studies have shown [36,37]. The scaffolds, as three-dimensional environments, have a particular advantage regarding the free cell proliferation surface provided by the inner channels, which can be even some orders of magnitude greater.

The former MTS assay, along with other experiments like porosity quantification, were decisive to exclude the scaffolds with $10 \mu \mathrm{m}$-diameter channels for some experiments and further in vitro cultures, in order to minimize the number of samples, otherwise unwieldy. Thus, some assays were performed only with scaffolds with $50 \mu \mathrm{m}$ diameter channels or the data obtained for the alternative scaffolds was considered of minor importance.

The RAD16-I filling represented a barrier for the penetration and migration of SCs along the channels, as it can be inferred from the absorbance value after 3 days in Figure 6A. Nevertheless, SCs rapidly recovered and proliferated the next 4 days, reaching a density similar to that of those seeded on scaffolds without RAD16-I, which suffered a gradual decrease in their population. Moreover, the mid-term proliferation enhancement differs from the chance of cells undergoing anoxic conditions as they migrate deeper, a common statement against non-degradable scaffolds. This hypothesis is supported by the results shown in Figure $6 \mathrm{C}$, where a significant difference in the number of cells after 10 days of culture can be seen, corroborating the trend anticipated in Figure 6A. Hence, whilst both strategies were found proper enough for in vitro cultures, the use of RAD16-I as a gel filling implied an improvement in medium-term SCs proliferation.

The fluorescence microscopy images (Figure 7B and C) confirmed the hypothesis that a number of cells migrated through the $50 \mu \mathrm{m}$ diameter channels, as previous assays suggested, even though most of the glial cells remained on the seeding surface. In 
addition, some of the cells found inside the channels had neuron morphology and phenotype (Figure $7 \mathrm{~B}_{1}$ and $\mathrm{C}_{1}$ ), as they did not express GFAP (but did express RFP) and showed sprouting. Some concatenated bundles of them (Figure $7 \mathrm{~B}_{3}$ and $\mathrm{C}_{3}$ ) joined together by membrane contacts to form structures up to $250 \mu \mathrm{m}$ long. Glial cells from different lineages were also identified (SCs in green and NSs-neuroglia in merged red and green) forming tight junctions between them inside the channels as well (Figure $7 \mathrm{~B}_{2}, \mathrm{~B}_{4}$ and $\mathrm{C}_{2}$ ). Remarkably, no immature NSs were detected in the seeding end of the scaffold after enzymatic dissociation, since NSs are prone to reaggregate and avoid migration in absence of differentiating cues. These images evidence that the channeled scaffolds allow glial cells to properly express their phenotype, organizing in clusters to produce extracellular matrix, and allow a fraction of the differentiated NSs to axially extend their cytoskeleton up to few hundreds microns. This bipolar extension of the neuron-like cells was a consequence of the shape, size and distribution of the channels, since their sprouts would have grown in an undetermined direction in larger pores or in an interconnected porous matrix. The peptide gel did not seem to have an effect in cells morphology or behavior, notwithstanding the proliferation issue discussed above.

As for the NGF release through the channels, the diffusion assay revealed a significant difference between the equilibrium reached when the RAD16-I filled the scaffold channels and in absence of it. These steady state values were, anyway, far from the $100 \%$ NGF, assuming that the factor was well distributed over the total volume of solution in the bottom compartment (Figure 8A). Given that the alternating hydrophobic/hydrophilic groups of cross-linked acrylate copolymers like P(EA-coHEA) has proven to effectively interact with domains of a number of proteins [38], it may be thought that part of the remaining NGF may have been adsorbed on the polymeric channels surfaces due to electrostatic coupling (and the rest could have 
diffused through the semi-hydrophilic polymeric matrix). In those channels filled by the RAD16-I peptide gel, part of the adsorption sites of the polymer surface are already occupied by the polypeptide chains and, thereby, a larger fraction of growth factor had to diffuse along the hydrogel phase, as occurs indeed. This factor-substrate interaction prevents the formation of a more efficient NGF chemotactic gradient in the longitudinal direction of the channels, but may anyway lead to a more beneficial environment for neural progenitors in terms of growth and differentiation than the gel alone, as they will be surrounded by a nanoenvironment containing the factor in each section of the guidance channel. A number of bonds between NGF and the peptides cannot, though, be discarded. Indeed, in $[\mathbf{3 9 , 4 0 ]}$ the authors observed a different motility of dyes and proteins through RAD16-I gel and attributed it to charge induced interactions between them. In this regard, NGF has also been found to bind to heparin- [41] and other peptides- [42] loaded in fibrin matrices.

The NGF quantitative analysis of the medium aliquots from SCs and NSs cultures revealed, however, a gradual increase in the cumulative amount of NGF released, even beyond the amount incorporated at the beginning of the experiment in the lower compartment (dashed line in Figure 8B). No significant differences were detected after 7 days between gel-filled and bare scaffolds, in spite of the differences discussed in Figure 8A. Considering that a fraction of the factor was as well adsorbed on the scaffold channels and diffused through the copolymer matrix, as occurred in the acellular experiments, the only explanation for this excess is that cultured cells synthesized more than an extra $150 \%$ of NGF by their own and maintained the concentration for at least 4 days. The chemical stimulation of neuroglia by the initial NGF loaded might have acted as a cue and lead them to synthesize it further up to their appropriate concentration. 


\section{Conclusions}

$\mathrm{P}($ EA-co-HEA) $90 / 10 \mathrm{w} / \mathrm{w}$ scaffolds with multiple 10 or $50 \mu \mathrm{m}$ diameter channels arranged lengthwise were obtained; such scaffolds have physicochemical properties similar to those of soft tissues in the central nervous system, in terms of density or mechanical behavior under compression. A polypeptide RAD16-I gel was used as channels filler to create a three-dimensional nanoenvironment, similar to the extracellular matrix in terms of consistency and composition. Early cell cultures in the multifunctional systems (scaffold + gel filling) revealed that the survival of cells seeded on one end of the scaffolds and invasion of the pores was related to the pores diameter, being those pores of $10 \mu \mathrm{m}$ in diameter too small to allow a free migration of the cells. Housing the cells in non-connected tubular pores allowed them to form complex structures, which were guided in the direction of the channels. On the other hand, the addition of the gel induced a slight mid-term benefit in terms of cell proliferation, provided that cells seeded on the end of the scaffold had already achieved to colonize the RAD16-I filling of the pores.

The development of a millimetric bicompartmental system enabled to study the diffusion rate of NGF, which is the main neurotrophin for axonal growth signaling, through the scaffolds channels. The chemotactic gradient established inside revealed a plausible interaction between NGF and the scaffold polymer surface. When seeded on the scaffolds in the presence of such gradient, neural and glial cells appeared to respond favorably in terms of proliferation and phenotype expression.

\section{Acknowledgements}

The authors acknowledge funding through the Spanish Ministerio de Ciencia e Innovación (MAT2011-28791-C03-02 and -03). Dr. J.M. García Verdugo (Department 
of Comparative Neurobiology, Cavanilles Institute of Biodiversity and Evolutive Biology, Universitat de València) is thanked for kindly providing the cells employed in this work. 


\section{References}

1. Walsh RA, Lynch T and Fahn S. Parkinson's Disease 2011 In: Hardiman O, Doherty CP, editors. Neurodegenerative Disorders. New York: Springer, p 77-114.

2. Damier P, Hirsch EC, Agid Y and Graybiel AM 1999 The substantia nigra of the human brain. II. Patterns of loss of dopamine-containing neurons in Parkinson's disease Brain 122 1437-48.

3. de Lau L and Breteler M 2006 Epidemiology of Parkinson's disease Lancet Neurol. 5 525-35.

4. Greenamyre TJ and Hastings TG 2004 Parkinson's--Divergent causes, convergent mechanisms Science 304 1120-22.

5. Kim SU and de Vellis J 2009 Stem cell-based cell therapy in neurological diseases: a review J. Neurosci. Res. 87 2183-2200.

6. Williams ZM, Neimat JS, Cosgrove GR and Eskandar EN 2005 Timing and direction selectivity of subthalamic and pallidal neurons in patients with Parkinson disease Exp. Brain Res. 162 407-16.

7. Gould E 2007 How widespread is adult neurogenesis in mammals? Nat. Rev. Neurosci. 8 481-88.

8. Lindvall O and Kokaia Z 2010 Stem cells in human neurodegenerative disorderstime for clinical translation? J. Clin. Invest. 120 29-40.

9. Park KI, Teng YD and Snyder EY 2002 The injured brain interacts reciprocally with neural stem cells supported by scaffolds to reconstitute lost tissue Nat. Biotechnol. 20 $1111-17$.

10. Subramanian A, Krishnan UM and Sethuraman S 2009 Development of biomaterial scaffold for nerve tissue engineering: Biomaterial mediated neural regeneration $J$. Biomed. Sci. 16 108-19. 
11. Yuan X 2010 Axon guidance and neuronal migration research in China Sci. China Life Sci. 53 304-14.

12. Delcroix GJ, Schiller PC, Benoit JP and Montero-Menei CN 2010 Adult cell therapy for brain neuronal damages and the role of tissue engineering Biomaterials 31 2105-20.

13. Kang KS et al 2014 Hybrid scaffold composed of hydrogel/3D-framework and its application as a dopamine delivery system J. Control. Release 175 10-16.

14. Vallés-Lluch A et al 2013 Combining self-assembling peptide gels with threedimensional elastomer scaffolds Acta Biomater. 9 9451-60.

15. Soria JM et al 2007 Influence of the substrate's hydrophilicity on the in vitro Schwann cells viability J. Biomed. Mater. Res. A 83 463-70.

16. Soria JM et al 2006 Survival and differentiation of embryonic neural explants on different biomaterials J. Biomed. Mater. Res. A 79 495-502.

17. Martínez-Ramos C et al 2012 Channeled scaffolds implanted in adult rat brain $J$. Biomed. Mater. Res. A 100 3276-86.

18. Cao H, Liu T and Chew SY 2009 The application of nanofibrous scaffolds in neural tissue engineering Adv. Drug Deliver. Rev. 61 1055-64.

19. Holmes TD, Lacalle S, Su X, Liu G, Rich A and Zhang S 2000 Extensive neurite outgrowth and active synapse formation on self-assembling peptide scaffolds Proc. Natl. Acad. Sci. U.S.A. 97 6728-33.

20. Takei J 2006 3-dimensional cell culture scaffold for everyone: drug screening, tissue Engineering and cancer biology. Alternatives to Animal Testing and Experimentation JSAAE 11 170-76.

21. Kopeček J and Yang J 2009 Peptide-directed self-assembly of hydrogels Acta Biomater. 5 805-16. 
22. McGrath AM, Novikova LN, Novikov LN and Wiberg M 2010 BD $^{\mathrm{TM}}$ PuraMatrix $^{\mathrm{TM}}$ peptide hydrogel seeded with Schwann cells for peripheral nerve regeneration Brain Res. Bull. 83 207-13.

23. Fon D et al 2014 Nanofibrous scaffolds releasing a small molecule BDNF-mimetic for the re-direction of endogenous neuroblast migration in the brain Biomaterials 35 $2692-2712$.

24. Song XY, Li F, Zhang FH, Zhong JH and Zhou XF 2008 Peripherally-derived BDNF promotes regeneration of ascending sensory neurons after spinal cord injury PLoS One 3 e1707.

25. Drinkut A, Tereshchenko Y, Schulz JB, Bähr M and Kügler S 2012 Efficient gene therapy for Parkinson's disease using astrocytes as hosts for localized neurotrophic factor delivery Mol. Ther. 20 534-43.

26. Freeman RS, Burch RL, Crowder RJ, Lomb DJ, Schoell MC, Straub JA and Xie L 2004 NGF deprivation-induced gene expression: after ten years, where do we stand? Prog. Brain Res. 146 111-26.

27. Madduri S, Papaloïzos M and Gander B 2009 Synergistic effect of GDNF and NGF on axonal branching and elongation in vitro Neurosci. Res. 65 88-97.

28. Vallés-Lluch A, Arnal-Pastor M, Martínez-Ramos C, Vilariño-Feltrer G, Vikingsson L and Monleón Pradas M 2013 Grid polymeric scaffolds with polypeptide gel filling as patches for infarcted tissue regeneration Conf. Pro.c IEEE Eng. Med. Biol. Soc. 2013 6961-4

29. Martínez-Ramos C, Rodríguez-Pérez E, Garnes MP, Chachques JC, Moratal D, Vallés Lluch A and Monleón Pradas M 2014 Design and assembly procedures for largesized biohybrid scaffolds as patches for myocardial infarct Tissue Eng. Part C Methods 20(10) $817-27$. 
30. Soler-Botija C, Bagó JR, Llucià-Valldeperas A, Vallés Lluch A, Castells-Sala C, Martínez-Ramos C, Fernández-Muiños T, Chachques JC, Monleón Pradas M, Semino CE and Bayes-Genis A 2014 Engineered 3D bioimplants using elastomeric scaffold, self-assembling peptide hydrogel, and adipose tissue-derived progenitor cells for cardiac regeneration Am. J. Transl. Res. 6(3) 291-301.

31. Castells-Sala C, Vallés-Lluch A, Soler-Botija C, Arnal-Pastor M, Martínez-Ramos C, Fernandez-Muiños T, Marí-Buyé N, Llucià-Valldeperas A, Sanchez B, Chachques JC, Bayes-Genis A, Monleón Pradas M and Semino CE 2015 Development of bioactive patch for maintenance of implanted cells at the myocardial infarcted site J. Nanomater. in press.

32. Lluch AV, Fernández AC, Ferrer GG and Pradas MM 2009 Bioactive scaffolds mimicking natural dentin structure J. Biomed. Mater. Res. B Appl. Biomater. 90 182-94. 33. Vallés Lluch A, Novella-Maestre E, Sancho-Tello M, Pradas MM, Ferrer GG and Batalla CC 2010 Mimicking natural dentin using bioactive nanohybrid scaffolds for dentinal tissue engineering Tissue Eng. Part A 16(9) 2783-93.

34. Diego, RN, Olmedilla MP, Aroca AS, Ribelles JL, Pradas MM, Ferrer GG and Sánchez MS 2005 Acrylic scaffolds with interconnected spherical pores and controlled hydrophilicity for tissue engineering J. Mater. Sci. Mater. Med. 16 693-98.

35. Mendis KK, Stalnaker RL and Advani SH 1995 A constitutive relationship for large deformation finite element modeling of brain tissue J. Biomech. Eng. 117 279-85.

36. Shimizu T et al 2006 Polysurgery of cell sheet grafts overcomes diffusion limits to produce thick, vascularized myocardial tissues FASEB J. 20 708-10.

37. Radisic M, Malda J, Epping E, Geng W, Langer R and Vunjak-Novakovic G 2006 Oxygen gradients correlate with cell density and cell viability in engineered cardiac tissue Biotechnol. Bioeng. 93 332-43. 
38. Gallego Ferrer G, Salmerón Sánchez M, Gómez Ribelles JL, Romero Colomer FJ and Monleón Pradas M 2007 Nanodomains in a hydrophilic-hydrophobic IPN based on poly (2-hydroxyethyl acrylate) and poly (ethyl acrylate) Eur. Polym. J. 43 3136-45.

39. Nagai Y, Unsworth LD, Koutsopoulos S and Zhang S 2006 Slow release of molecules in self-assembling peptide nanofiber scaffold J. Controlled Release 11518 25.

40. Gelain F, Unsworth LD and Zhang S 2010 Slow and sustained release of active cytokines from self-assembling peptide scaffolds J. Control. Release 145 231-9.

41. Lee AC, Yu VM, Lowe JB, Brenner MJ, Hunter DA, Mackinnon SE and SakiyamaElbert SE 2003 Controlled release of nerve growth factor enhances sciatic nerve regeneration. Exp. Neurol. 184 295-303.

42. Willerth SM, Johnson PJ, Maxwell DJ, Parsons SR, Doukas ME and SakiyamaElbert SE 2007 Rationally designed peptides for controlled release of nerve growth factor from fibrin matrices J. Biomed. Mater. Res. A 80 13-23. 


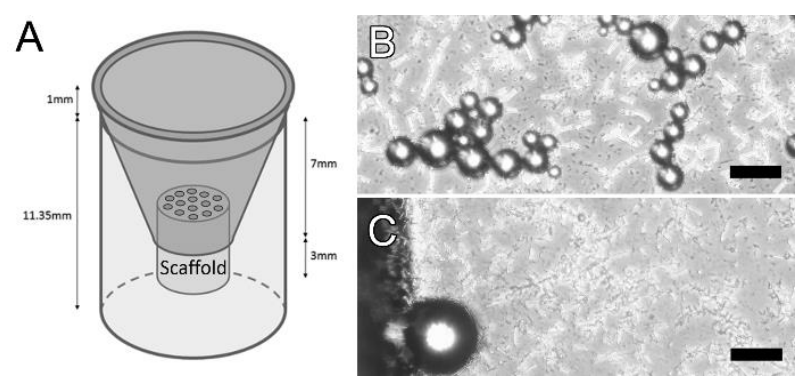

Figure 1. A. Scheme of the bicompartmental system constituted by the cylindrical scaffold assembled to the conical reservoir, which is set on a well of a 96-well culture plate. Optical microscopy images from the bottom compartment of the bicompartmental system in the watertightness experiment with a PMMA spheres aqueous suspension, which diameter was smaller (B) or higher than 100 microns (C). Particle in image C illustrates one of the two only large spheres found in the bottom compartment in the experiment. Scale bar: $100 \mu \mathrm{m}$.
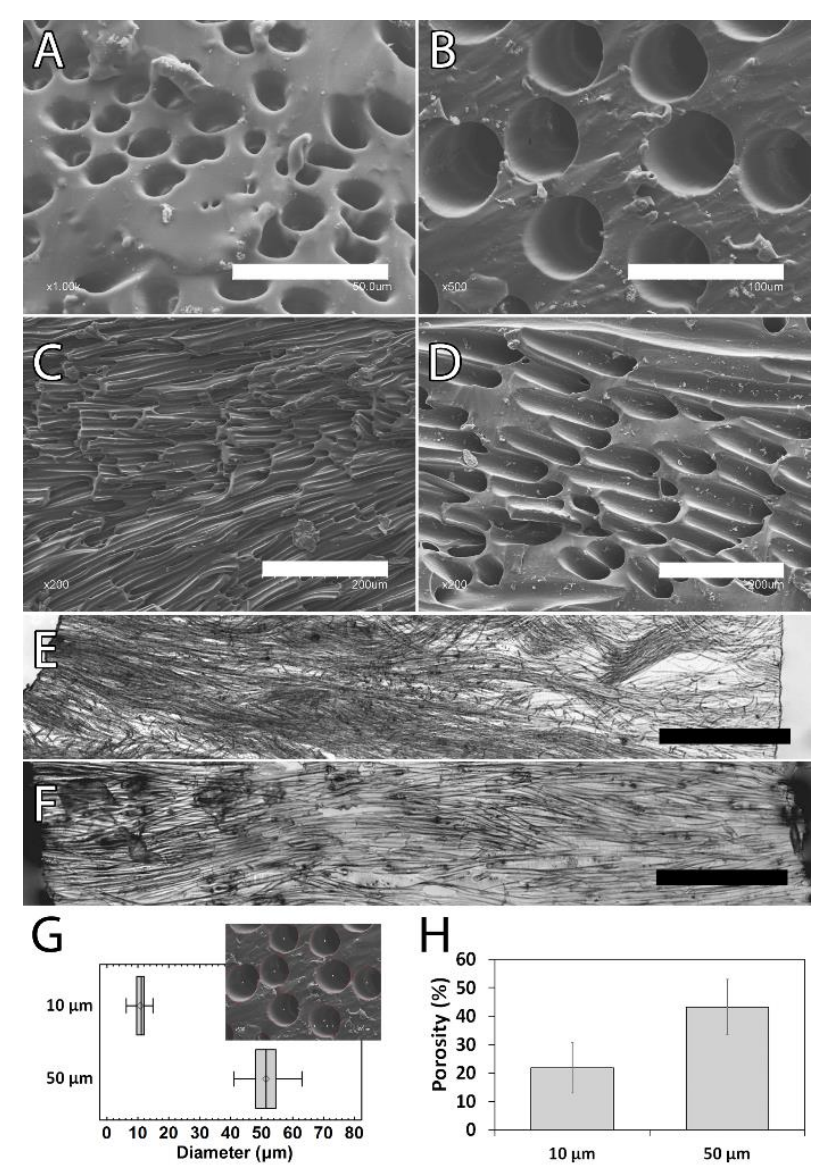

Figure 2. SEM images of cross $(\mathbf{A}, \mathbf{B})$ and longitudinal $(\mathbf{C}, \mathbf{D})$ sections of $\mathrm{P}(\mathrm{EA}-\mathrm{co}-$ HEA) $90 / 10$ scaffolds with $10($ A, C) and $50 \mu \mathrm{m}$ (B, D) diameter channels. Bright field images reconstruction of $100 \mu \mathrm{m}$ thick sections of channeled scaffolds of 10 (E) and 50 $\mu \mathrm{m}(\mathbf{F})$ in pores diameter. G. Box-and-whisker plot of the pore diameter calculated with the ImageJ software and detail of a processed image. H. Bar chart of the porosity calculated from the porous area. Scale bar: $50 \mu \mathrm{m}(\mathbf{A}), 100 \mu \mathrm{m}(\mathbf{B}), 200 \mu \mathrm{m}(\mathbf{C}, \mathbf{D}), 1$ $\mathrm{mm}(\mathbf{E}, \mathbf{F})$. 


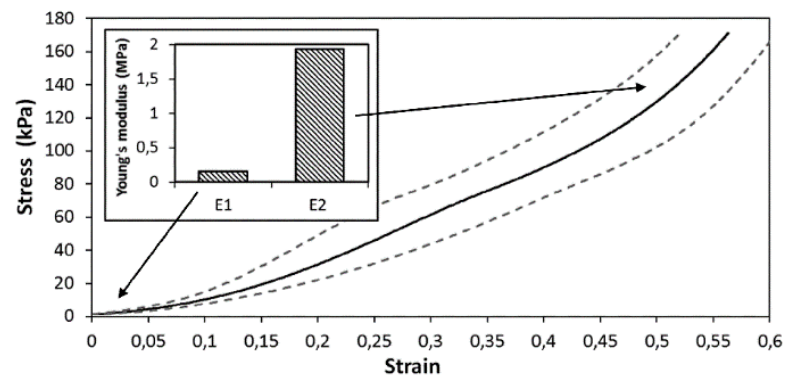

Figure 3. Average stress-strain curve for the mechanical compression analyses of $\mathrm{P}$ (EA-co-HEA) 90/10 scaffolds with $50 \mu \mathrm{m}$-diameter channels. The interval $\pm \mathrm{SD}$ is represented by the dashed lines. The embedded chart shows the elastic moduli for the linear regions $\mathrm{E}_{1}$ (0 to $9 \%$ strain) and $\mathrm{E}_{2}$ (54 to $56 \%$ strain) of the scaffold behavior.

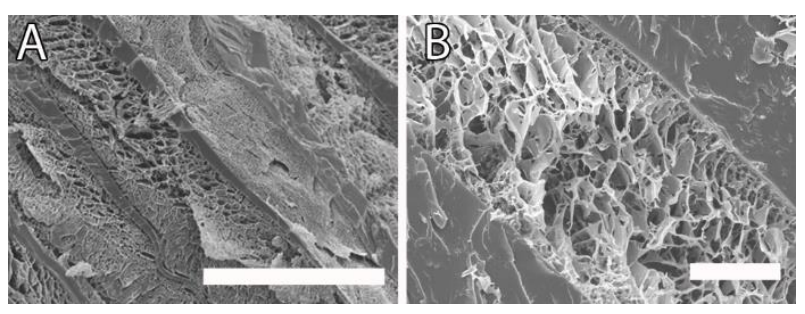

Figure 4. CryoSEM images of longitudinal sections of $50 \mu \mathrm{m}$-diameter channeled scaffolds with RAD16-I gelled in situ in the pores. Scale bars: $80 \mu \mathrm{m}$ (A), $20 \mu \mathrm{m}$ (B).

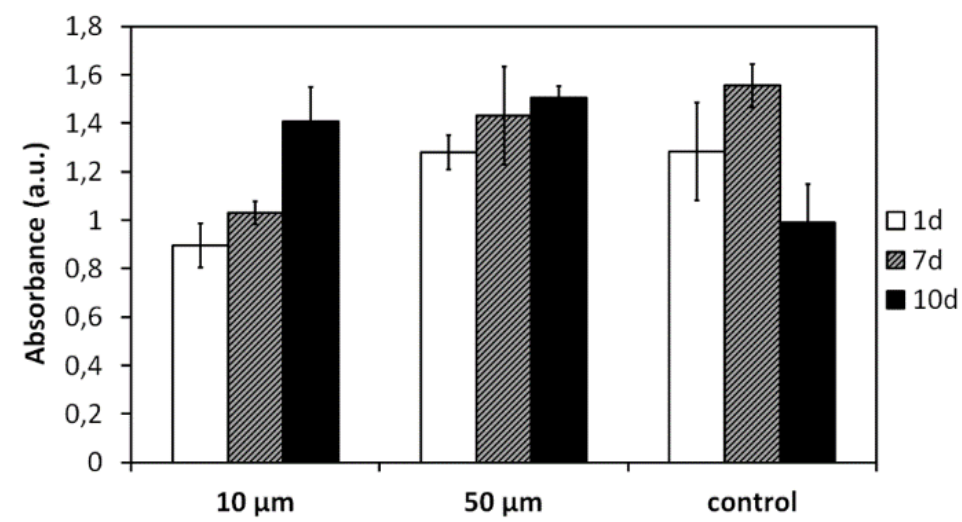

Figure 5. Results from the MTS assay of SCs cultured for 1, 7 and 10 days in scaffolds with 10 and $50 \mu \mathrm{m}$-diameter channels without RAD16-I and on a culture plate well (control). Bars represent the average value \pm SD. 

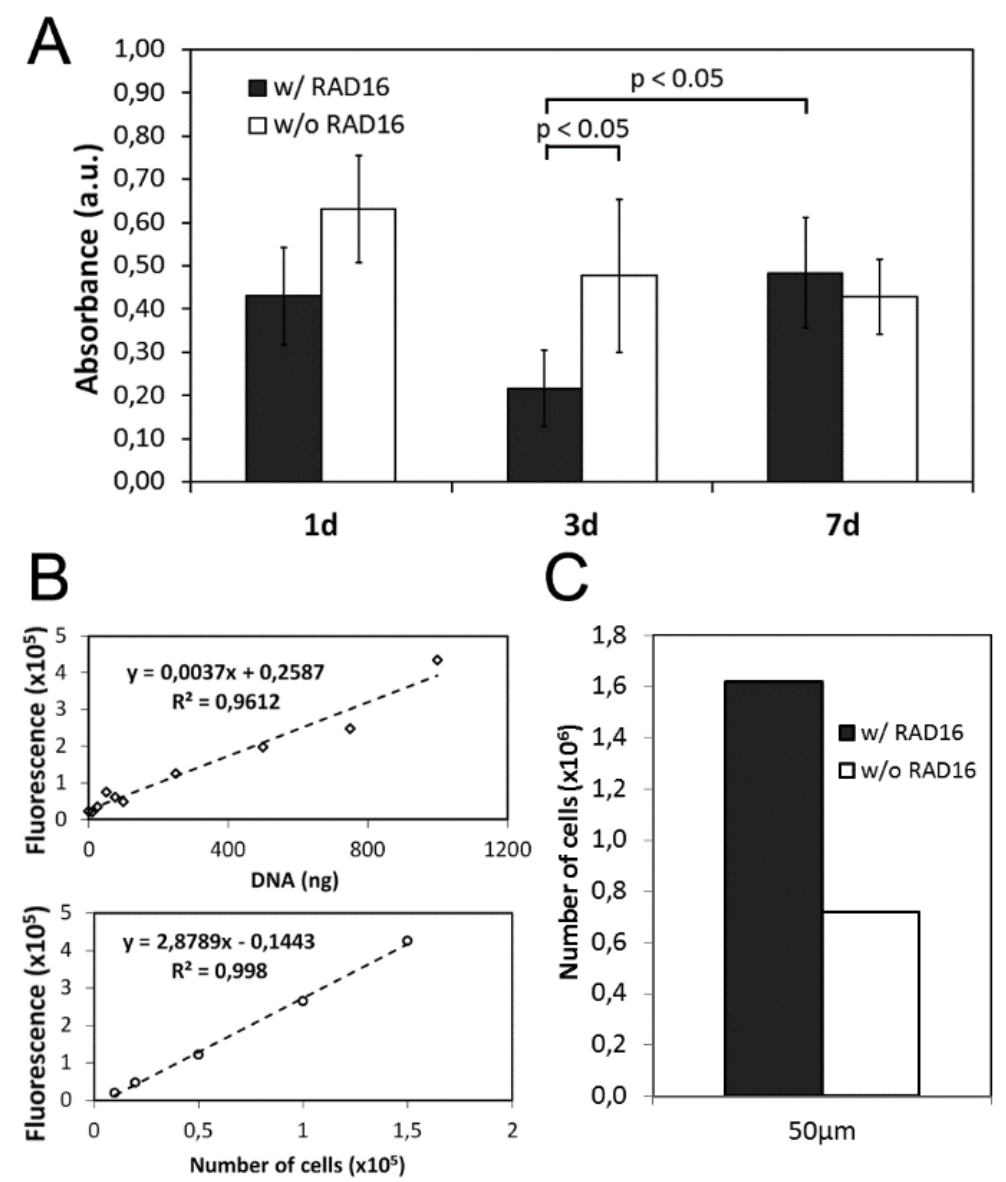

Figure 6. A. Results from the MTS assay of SCs and NFs cocultured for 1, 3 and 7 days in scaffolds with $50 \mu$ m-diameter channels filled (w/) and non-filled (w/o) with RAD16I. Bars represent the average value \pm SD. The differences between groups are presented with corresponding p-value when statistically significant. B. Standard linear approximations of the measured fluorescence for different amounts of bovine thymus DNA (top) and different SCs densities (bottom) for the DNA assay. The linear least squares equations and their corresponding coefficients of determination are shown. $\mathbf{C}$. DNA fluorescence assay bar chart representing the number of cells after a 10 days culture of SCs in scaffolds with $50 \mu$ m-diameter channels with and without RAD16-I. 

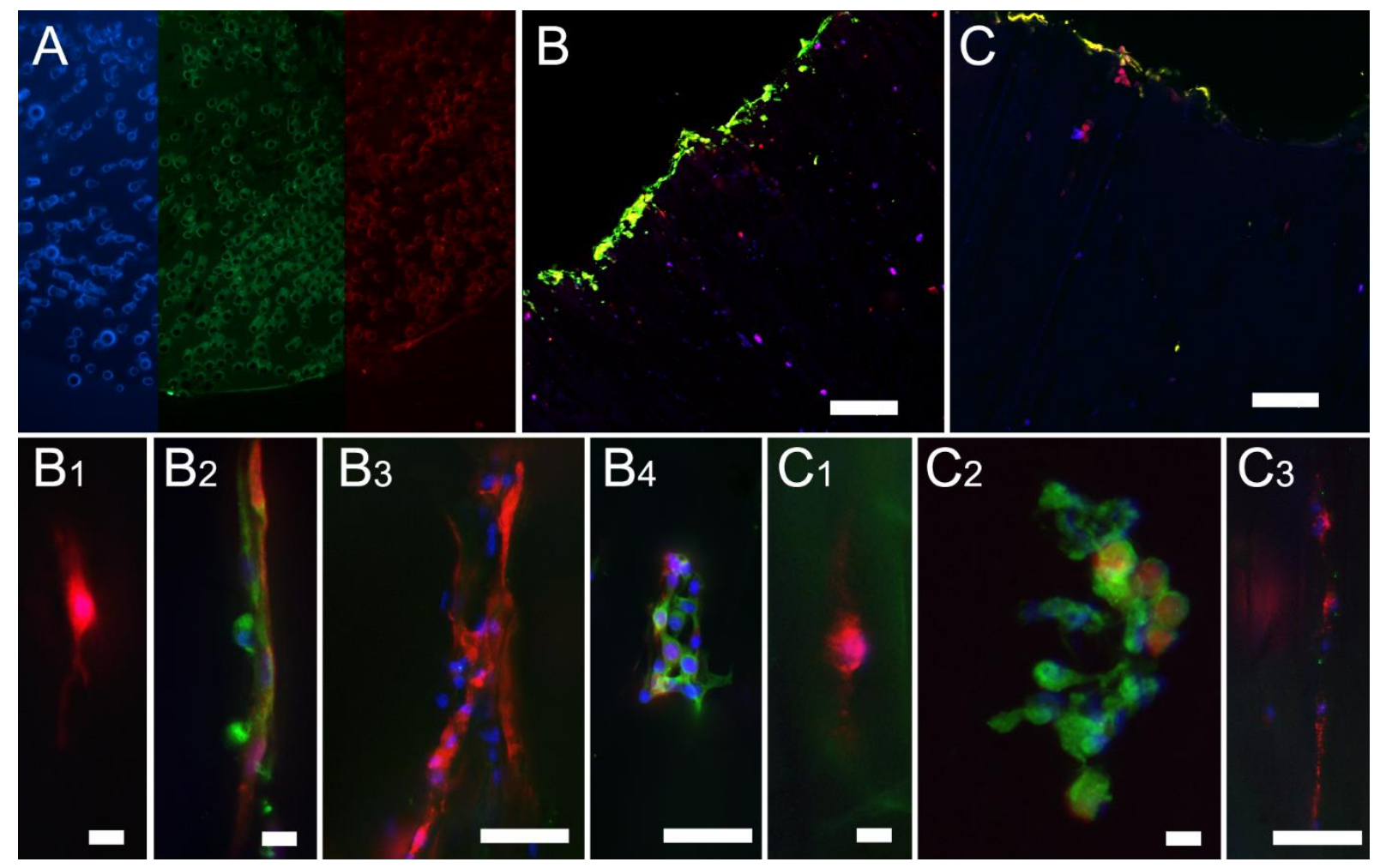

Figure 7. Fluorescence (A, D, E) and confocal microscopy $(\mathbf{B}, \mathbf{C})$ images of scaffolds with $50 \mu \mathrm{m}$ diameter channels after 7 days of SCs and NFs co-culture. (A). Inherent self-fluorescence of P(EA-co-HEA) 90/10 at 465, 530 and $670 \mathrm{~nm}$ of emission (left to right, respectively). Longitudinal sections at the cell seeding end of scaffolds with the channels empty (B) or filled with RAD16-I (C). Details of inner areas of longitudinal sections of scaffolds without (subscripted B) or with RAD16-I (subscripted C) in their channels. Blue $=$ DAPI; green $=$ GFAP; red $=$ RFP. Scale bars: $200 \mu \mathrm{m}(\mathbf{B}, \mathbf{C}), 50 \mu \mathrm{m}$ $\left(\mathbf{B}_{3}, \mathbf{B}_{\mathbf{4}}, \mathbf{C}_{\mathbf{3}}\right)$ and $10 \mu \mathrm{m}\left(\mathbf{B}_{\mathbf{1}}, \mathbf{B}_{\mathbf{2}}, \mathbf{C}_{\mathbf{1}}, \mathbf{C}_{\mathbf{2}}\right)$. 

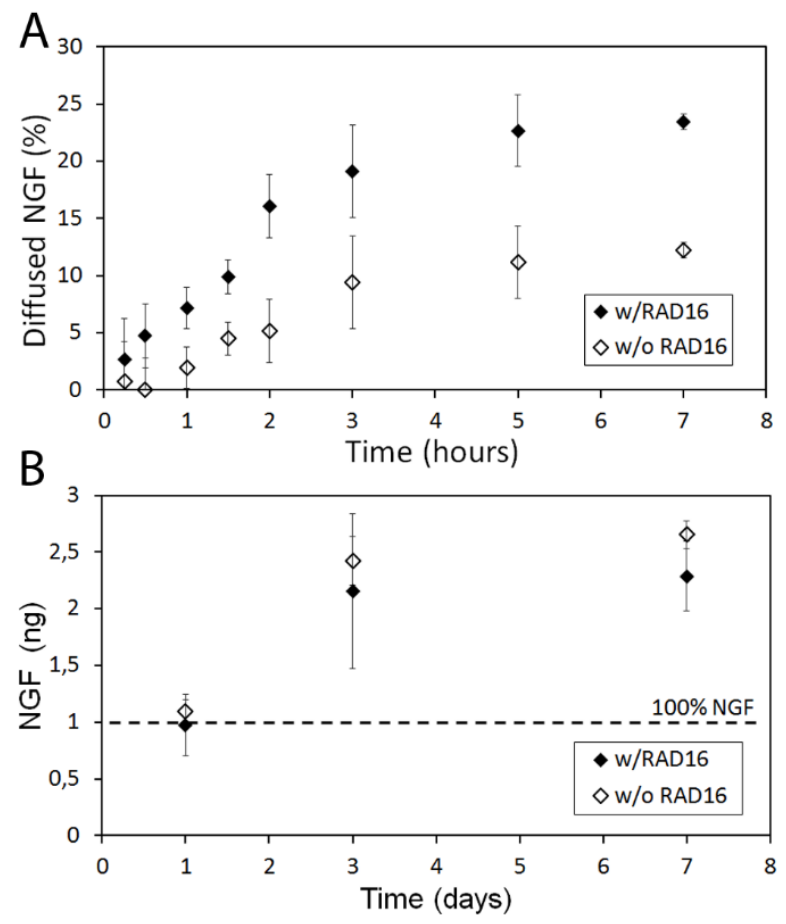

Figure 8. A. Plot of the NGF mass fraction (\%) released to the upper compartment of the bicompartmental system on the basis of the total initial amount loaded in the bottom compartment, in systems with empty or RAD16-I filled scaffolds. B. Cumulative released NGF mass during the SCs and NFs coculture at 1, 3 and 7 days in bicompartimental systems with and without RAD16-I. The dashed horizontal line represents the NGF mass incorporated to the medium of the bottom compartment at the beginning of the experiment and thus available for diffusion. 